\title{
Kidney morphological changes in relation to long-term renal function and metabolic control in adolescents with IDDM
}

\author{
U. B. Berg ${ }^{1}$, T. B. Torbjörnsdotter ${ }^{1}$, G.Jaremko ${ }^{2}$, B. Thalme ${ }^{1}$ \\ ${ }^{1}$ Department of Pediatrics, Karolinska Institute, Huddinge University Hospital, Huddinge, Sweden \\ ${ }^{2}$ Department of Pathology, Karolinska Institute, Huddinge University Hospital, Huddinge, Sweden
}

\begin{abstract}
Summary For the past $10-15$ years all the children at our unit with insulin-dependent diabetes mellitus have been repeatedly followed-up with renal function tests. Renal biopsy, examined by light and electron microscopy, was included in the follow-up of 36 adolescents and young adults, aged 13-25 years, with a disease duration of 7-19 years. All subjects had undergone at least three renal function tests before biopsy and none had persistent microalbuminuria. Renal function was evaluated as glomerular filtration rate and effective renal plasma flow determined by clearances of inulin and para-amino hippuric acid. Glomerular filtration rate and filtration fraction were increased before and at the time of the biopsy. Glomerular basement membrane thickness (331-858 nm) and mesangial matrix volume fraction (7.4-17.1\%) were increased. Long-term hyperfiltration and hyperperfusion before biopsy correlated inversely with mean glomerular volume. Increased filtration fraction before the biopsy correlated directly with mean of all $\mathrm{HbA}_{1 \mathrm{c}}(r=0.485, p<0.01)$ and both variables cor-
\end{abstract}

related directly with mesangial matrix volume fraction, basement membrane thickness and structural in$\operatorname{dex}(r=0.433, p<0.01$ and $r=0.626, p<0.001$, respectively). Urinary albumin excretion rate correlated directly with foot process width $(r=0.645, p<0.001)$. By multiple regression analysis the most important variable for the increase in basal membrane thickness was the metabolic control while the mean of previous filtration fraction was most important for the increase in mesangial matrix volume. In conclusion, although none of the patients showed constant microalbuminuria, early diabetic structural changes were evident with basal membrane thickening and increased mesangial matrix volume. The structural changes related to long-standing hyperfiltration and poor metabolic control. [Diabetologia (1998) 41: 1047-1056]

Keywords Kidney biopsy, insulin-dependent diabetes mellitus, kidney function tests, adolescents, glomerular filtration rate, diabetic nephropathy, kidney morphology.
Received: 11 August 1997 and in final revised form: 8 March 1998

Corresponding author: U.Berg, M.D., Department of Pediatrics, Huddinge University Hospital, S-14186 Huddinge, Sweden

Abbreviations: IDDM, Insulin-dependent diabetes mellitus; UAE, urinary albumin excretion rate; GFR, glomerular filtration rate; ERPF, effective renal plasma flow; PAH, para-amino hippuric acid; FF, filtration fraction; BSA, body surface area; FPLC, fast protein liquid chromatography; GV, glomerular volume; $\mathrm{Vv}$ (mes/glom), mesangial volume fraction per glomerulus; $\mathrm{Vv}$ (matrix/glom), mesangial matrix volume fraction per glomerulus; Sv(pcap/glom), the surface density of the peripheral capillary walls; Lv(slit pore/glom), the length density of filtration slits; BMT, basal membrane thickness.
Diabetic nephropathy is a life threatening complication of insulin-dependent diabetes mellitus (IDDM). Thirty to forty percent of patients with IDDM will develop terminal renal failure $[1,2]$. Some new data suggest a lower incidence of nephropathy [3-5] but others do not [6]. Since 1978 we have longitudinally followed all the diabetic children at our unit with renal function tests every second to third year after onset. Cross-sectional renal biopsy was performed in patients with a disease duration of more than 5 years and a patient age of more than 12 years regardless of the presence of microalbuminuria. The aim of the present study was to investigate the relationship between actual and previous long-term renal function, 
long-term metabolic control and renal biopsy findings in an unselected group of patients to predict those at risk of nephropathy.

\section{Subjects and methods}

Patients. At our pediatric clinic in Huddinge Hospital, all diabetic patients older than 12 years and with a disease duration of more than 5 years, were asked to participate in the kidney biopsy study in connection with their regular functional follow-up investigation. The study was approved by the ethical committee of Karolinska Institute and was performed after informed consent from the patients and parents. Since the primary aim of the present study was to investigate the influence of previous renal function on structural changes, only patients who had completed at least three renal function tests were included. None of these had persistent microalbuminuria. The patients were, however, not selected on the basis of the albumin excretion rate.

Out of the 45 possible subjects, 36 accepted to participate while 9 declined or wished to perform the biopsy at a later date. These 9 patients did not differ in age at onset of the disease, previous or actual renal function, blood pressure, proteinuria or metabolic control from those who agreed to participate in the study.

We investigated 17 girls and 19 boys. The age of the patients at the time of the biopsy varied between 13.2 and 25.2 (median 18.6) years, and the duration of the disease was between 7.5 and 19.2 (median 10.8) years. The age at onset of the disease was 0.6 to 12.1 (median 7.4 ) years. None of the patients had persistent microalbuminuria defined as greater than $15 \mu \mathrm{g} / \mathrm{min}$ in two of three urine samples taken at least 3 months apart. None of the patients had bacteriuria and none was on antihypertensive treatment.

The investigations were performed over 3 days. On the first day a renal function test was performed. Overnight urine was collected the first night for determination of albumin excretion rate (UAE). On the second day a renal biopsy was taken. After the biopsy the patients were kept in a supine position for $24 \mathrm{~h}$ with repeated control of the pulse rate and the blood pressure. No complications were experienced except for slight pain in the muscles above the biopsy site.

Renal function tests. Renal function was evaluated every second to third year from the onset of the diabetic disease. Glomerular filtration rate (GFR) and effective renal plasma flow (ERPF) were determined by the clearances of inulin and para-amino hippuric acid (PAH) during water diuresis with a standard clearance technique $[7,8]$. The patients were given their normal insulin dose followed by breakfast in the morning before the start of the renal function test. Water diuresis was induced by an oral water intake of $20 \mathrm{ml} / \mathrm{kg}$ body weight during the first hour and thereafter $5 \mathrm{ml} / \mathrm{kg}$ every $30 \mathrm{~min}$. After an intravenous prime dose of inulin and $\mathrm{PAH}$, a continuous infusion was given. After an equilibration period of $1 \mathrm{~h}$, four 30 min urine collection periods were performed and midway through each collection period a blood sample was drawn. GFR and ERPF are presented as the mean values of the four clearance periods and are corrected for body surface area. Filtration fraction $(\mathrm{FF})$ is calculated as GFR/ERPF.

Inulin in blood and urine was determined by the anthrone method [9] and PAH by a modified Smith technique [10].

The number of renal function tests performed in each patient was 3-7 (median 5). The mean GFR, ERPF and FF of all previously performed renal function tests was calculated for each patient as well as the slope of GFR in relation to time for each patient. Since GFR increased from onset to 2 years, duration the slope value of GFR was calculated for each patient after 2 years, duration.

Renal function was compared with that of 59 healthy children and young adults (3.5-25.9 [median 13.2] years). The age range of the control subjects corresponds to the age range of the diabetic patients during the whole follow-up period.

Urine samples. Timed overnight collected urine was analysed for albumin by an automated immuno-nephelometric method (Behring Nephelometer Analyser; Behringwerken AG, Marburg, Germany) and UAE was determined.

Metabolic control. Since 1980 total $\mathrm{HbA}_{1}$ has been analysed by ion exchange chromatography using Isolab's Fast Hemoglobin Test System (Quick-Step Fast Hemoglobin Test System; Isolab Inc., Akron, Ohio, USA). Reference values were 5.5-8.5\%. From $1986 \mathrm{HbA}_{1 \mathrm{c}}$ was determined by the FPLC method (Fast Protein Liquid Chromatography; Pharmacia, Uppsala, Sweden) [11]. Normal reference values were $3.4-5.0 \%$. In an attempt to compare glycaemic control over time, $\mathrm{HbA}_{1}$ data were converted to $\mathrm{HbA}_{1 \mathrm{c}}$ using the equation $\mathrm{HbA}_{1}=1.13 \times$ $\mathrm{HbA}_{1 \mathrm{c}}+0.85$. The correlation coefficient between the two methods was 0.957 in our laboratory. $\mathrm{HbA}_{1}$ or $\mathrm{HbA}_{1 \mathrm{c}}$ was followed in each patient 3-4 times a year. Mean $\mathrm{HbA}_{1 \mathrm{c}}$ was calculated for each year and the mean of all years was calculated as a measure of metabolic control. The $\mathrm{HbA}_{1 \mathrm{c}}$ was measured on the day of renal function.

Renal biopsy. All biopsies were performed under local anaesthesia with ultrasound guidance using a fixed adapter (3.5 MHz; Acuson, Mountain View, Calif., USA) with the aid of an automatic biopsy device (Biopty Bard Urological, Covington, Ga, USA) with a 16 gauge needle (Manan Medical Products, Northbrook, Ill., USA). Samples for light and electron microscopy were immediately immersed in $4 \%$ paraformaldehyde in phosphate buffer. Parts of cortical tissue were postfixed for electron microscopy in $2 \%$ glutaraldehyde and $4 \%$ paraformaldehyde in phosphate buffer and embedded in Polybed 812 . The remaining fixed tissue was embedded in glycolmethacrylate (Technovit 7100, Kulzer, Germany) for light microscopy. A subdivided part of fresh cortical tissue was promptly snap-frozen in liquid nitrogen and cut in a cryostat at a thickness of $6 \mu \mathrm{m}$. After being rinsed in phosphate buffered saline, the sections were investigated by direct method using fluorescein isothiocyanate-conjugated antibodies to human IgG, IgA, IgM, C3, C1q (Dakopatts AB, Stockholm, Sweden) followed by rinsing. Subsequently, the sections were airdried, coverslipped with Pertex (Histolab, Gothenburg, Sweden) and examined in a Zeiss epifluorescence microscope with appropriate filters (Carl Zeiss, Oberkochen, Germany).

Light microscopy. The mean glomerular volume (GV) was estimated by Cavalieri's principle [12]. The glycolmethacrylate embedded tissue blocks were serially sectioned in $2.5 \mu \mathrm{m}$ thick sections and stained with periodic acid-Schiff. The glomeruli were sampled in that order as they successively became visible in the sections. The first profile of a glomerulus was sampled in the section in which its capillary loops first became visible and thereafter followed through the consecutive sections in which the following profile areas were sampled at $10-\mu \mathrm{m}$ intervals, i.e. at every fourth section. The number of sampled levels per glomerulus ranged from 13 to 21 . The area of the profiles was estimated by point counting (Ptot) using an ocular grid with $19.9 \mu \mathrm{m}$ between each point $(\mathrm{d})$ at tissue level $(410 \times)$. The sum of the profile areas (SUM A) were estimated according 
the formula SUM A $=$ Ptot $\times \mathrm{d}^{2}$. For the final calculation of the glomerular volume the mean of the actual section thickness $(\mathrm{t})$ was estimated by a method based on confocal microscopy, as described elsewhere [13]. In short, the $\mathrm{x}-\mathrm{Z}$ profile of a section is scanned by confocal microscopy and the full width half maximum of the obtained intensity profile in the axial direction is used as an estimate of the actual section thickness. The precision of the method has been shown to be $\pm 100 \mathrm{~nm}$ [13]. The glomerular volume was then calculated as: SUM A $\times 4$ t. In each biopsy at least five glomeruli were measured and the mean GV was calculated.

A few biopsies contained deep juxta-medullary glomeruli with substantially larger volumes compared with glomeruli in more superficial cortical layers. A glomerulus was defined as juxta-medullary only when it was clearly and directly seen abutting medullary tissue. When the sampling procedure given above was strictly followed in the biopsies containing juxtamedullary glomeruli, the mean GV reached a substantially higher value. Juxta-medullary glomeruli (as defined above) were therefore excluded in order to assess mean $\mathrm{GV}$ based on estimates of a more homogenous population of glomeruli representative for all the analysed biopsies.

Electron microscopic quantitation. The plastic blocks obtained for electron microscopy were randomly selected for sampling of five glomeruli. From the surface of a block $1-\mu \mathrm{m}$ thick sections were cut, stained with toluidine blue and inspected by light microscopy. No glomeruli were sampled from this level of the blocks. $1-\mu \mathrm{m}$ thick sections were then collected at sequential $50 \mu \mathrm{m}$ levels until new glomeruli appeared which were then sampled for thin sectioning in the order that they appeared. Incomplete glomeruli at the edges of the blocks were excluded. Seven to 19 electron micrographs, covering approximately $40 \%$ of the total area of each glomerulus, were taken at approximately 10000 magnification in a systematic random manner. This was achieved by moving the specimen stage of the electron microscope (Philips 420, Eindhoven, The Netherlands) between predetermined points. The final magnification was corrected using a grating grid (EF Fullan, Inc., 28800 lines/inch). Glomerular profiles representing less than seven sampling areas were excluded. The reference space, in the following termed "glomerulus", was defined as a minimal convex polygon enclosing the glomerular tuft (i.e. tuft plus entrapped urinary space within the polygon) [14]. The geographical definition of the mesangium and its delineation to the peripheral capillary wall, was applied as in the study of Østerby and Gundersen [14]. All the estimated relative structural quantities given below were expressed in relation to this reference space. The number of points counted per biopsy varied between 1643 and 2852 (median 2116), the number of intercepts 720-1489 (median 1005) and the number of filtration slits 2569-5017 (median 3715).

Mesangial and mesangial matrix volume fractions per glomerulus, (Vv(mes/glom) and Vv(matrix/glom)), were estimated by point counting using a superimposed lattice square grid with points $30 \mathrm{~mm}$ apart. Total points hitting the mesangial areas and the mesangial matrix substance respectively, were divided with the total points hitting the reference space of the glomerular tuft. Mesangial matrix was defined as all extracellular material in the mesangial areas.

Using the same square lattice grid as above the intersections (I) with the epithelial aspect of the basement membrane of the peripheral capillary walls were counted and the surface density of the peripheral capillary walls, $\mathrm{Sv}$ (pcap/glom), was calculated according to:

$\mathrm{Sv}($ pcap/glom $)=2 \times \mathrm{I} /(\mathrm{P} \times(2 \mathrm{~d} / \mathrm{mag}))\left(\mu \mathrm{m}^{-1}\right)$ and the number of their related filtrations slits $(\mathrm{Q})$, the length density of filtration slits ( $\mathrm{Lv}$ (slit pore/glom)), was estimated as:

$\mathrm{Lv}($ slit pore/glom $)=2 \times \mathrm{Q} /\left(\mathrm{P} \times\left(\mathrm{d}^{2} / \mathrm{mag}^{2}\right)\right)\left(\mu \mathrm{m}^{-2}\right)$.

In the formulas above, $\mathrm{P}=$ total points within the reference space, $\mathrm{d}=$ distance between each point of the grid and mag = final magnification.

The mean foot process width was estimated as the ratio of $\mathrm{Sv}$ (pcap/glom) and $\mathrm{Lv}$ (slit pore/glom).

The basement membrane thickness (BMT) was estimated using the orthogonal intercept method of Jensen and co-workers [15].

The structural index was calculated according to Østerby et al. [16] as: Structural index $=(\mathrm{BMT} / 10)+100 \mathrm{Vv}$ (matrix/ glom $)+\%$ occluded glomeruli. None of our patients showed any occluded glomeruli.

Statistical analyses. When comparing different variables attention was paid to whether the variable was measured in absolute values or related to body size. Mean values \pm SEM or range with median values are given. Data presented by box plots illustrate the median, 25th and 75th, and 10th and 90th percentiles. The fall in GFR and ERPF was calculated for each patient from the slope of individual values against time. Student's $t$-test and Mann-Whitney test were used. The $p$-values given in the paper are those calculated by the Student's $t$-test. These $p$ values were in good agreement with those calculated by the Mann-Whitney test. UAE is given log 10 transformed for calculations because of a skewed distribution. Linear regression analyses were performed according to the least square method. Multiple regression analyses have been used for evaluating the influence of different variables on BMT and $\mathrm{Vv}$ (matrix/glom). The statistical program of JMP version 3.1 was used. A $p$-value below 0.05 was regarded significant.

\section{Results}

Renal morphology. By light microscopy no obvious or a very slight thickening of the glomerular capillary walls and the mesangial areas were seen. In some biopsies mild focal hyaline arteriosclerosis close to the glomerular vascular poles was noted. No interstitial fibrosis, tubular atrophy or global glomerular sclerosis were seen.

By immunofluorescene microscopy four out of 36 patients showed diffuse positive staining for IgA and $\mathrm{C} 3$ in the mesangium. By light microscopy no obvious mesangial proliferative changes were identified in these patients. When comparing patients with $\operatorname{IgA}$ deposits with those without, no significant differences in actual or previous renal function, BMT, $\mathrm{Vv}$ (matrix/glom), $\mathrm{Vv}$ (mes/glom), UAE, blood pressure or incidence of haematuria were found. The only difference found between the two groups was that the patients with $\operatorname{IgA}$-deposits showed larger $\mathrm{GV}$ than those without $\left(3.5 \pm 0.4\right.$ vs $2.6 \pm 0.1 \mathrm{M \mu}^{3} /$ $1.73 \mathrm{~m}^{2}, p<0.01$ ).

A correlation, although not significant, was found between mean GV and body surface area (BSA, $r=0.311, p=0.078$ ) but not between mean GV and age. Mean GV was therefore related to $1.73 \mathrm{~m}^{2}$ 
BSA. Mean GV varied between 1.7 and 4.6 (median 2.7) $\mathrm{M \mu m}^{3} / 1.73 \mathrm{~m}^{2}$. The coefficient of variation of mean GV was $21 \%$.

Electron microscopy showed BMT varying between 331 and 858 (median 496) nm, Vv(mes/glom) between 14.1 and 26.8 (median 19.1) \% and $\mathrm{Vv}(\mathrm{ma}-$ trix/glom) between 7.4 and 17.1 (median 10.7)\%. Figure 1 shows a strong positive correlation between BMT and $\mathrm{Vv}$ (matrix/glom). BMT and $\mathrm{Vv}$ (matrix/glom) did not correlate to age or duration of disease.

Previous renal function. Figure 2 shows GFR, ERPF and $\mathrm{FF}$ at different periods of time from onset of the disease with all investigations performed in the patients. Median GFRs during the first 10 years from onset were significantly $(p<0.001)$ higher than that of the control subjects, while GFR after more than 14 years did not differ from that of the control subjects. ERPF did not differ from that of the control subjects except after 8 and 12 years when it was significantly $(p<0.05)$ lower than that of control subjects. FF was significantly $(p<0.001)$ increased after 2 years' duration and onwards. The median slope values of GFR and ERPF, calculated from the individual slope values of each patient after 2 years' duration, were -1.1 (range -5.5 to 6.7 ) and -6.5 (range -43.7 to 34.7$) \mathrm{ml} / \mathrm{min}$ per $1.73 \mathrm{~m}^{2}$ and year, respectively. There was a significant fall in both GFR and ERPF with time ( $p=0.01$ and $<0.01$, respectively, the median slope values compared to the null hypothesis). A significant $(p=0.02)$ decrease in GFR was also seen when analysis of variance (ANOVA) repeated measures analysis was made in those 16 patients repeatedly investigated at 2, 5, 8 and 10 years' duration.

Actual renal function and $U A E$. GFR and FF at the time of biopsy were significantly $(<0.001)$ higher in the diabetic patients than in 59 healthy control subjects $\left(131 \pm 4 \mathrm{vs} 116 \pm 1 \mathrm{ml} / \mathrm{min}\right.$ per $1.73 \mathrm{~m}^{2}$ and $22.7 \pm 0.7$ vs $19.0 \pm 0.3 \%$ ) while ERPF did not differ $\left(596 \pm 22\right.$ vs $619 \pm 11 \mathrm{ml} / \mathrm{min}$ per $\left.1.73 \mathrm{~m}^{2}\right)$.

UAE during the night before the renal function test varied between 2 and 64 (median 6) $\mu \mathrm{g} / \mathrm{min}$. Thus, eight of the patients had microalbuminuria the night before the renal biopsy defined as a UAE above $15 \mu \mathrm{g} / \mathrm{min}$ while none of them had had persistent microalbuminuria before the biopsy. When grouping the patients into those with microalbuminuria $(>15 \mu \mathrm{g} / \mathrm{min})$ and those without at time of renal biopsy, patients with microalbuminuria had higher mean previous GFR and FF than patients without microalbuminuria $(146 \pm 5 \mathrm{vs} \quad 133 \pm 3 \mathrm{ml} / \mathrm{min}$ per $1.73 \mathrm{~m}^{2}, p<0.05$ and $23.6 \pm 0.3$ vs $21.9 \pm 0.4 \%, p=$ 0.01 respectively). A direct correlation was found between $\log$ UAE and mean previous FF $(r=0.417$, $p<0.05)$ but no correlation was found between log UAE and mean previous GFR or ERPF.

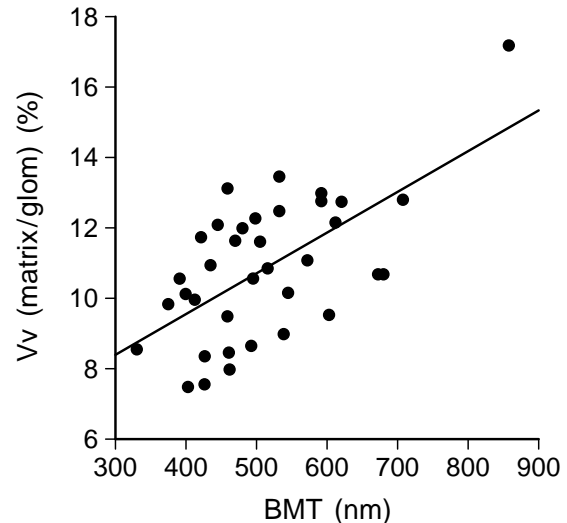

Fig. 1. Relation between glomerular basal membrane thickness (BMT) and mesangial matrix volume fraction ( $\mathrm{Vv}$ (matrix/glom)). The correlation coefficient $r=0.612, n=36, p<$ 0.001
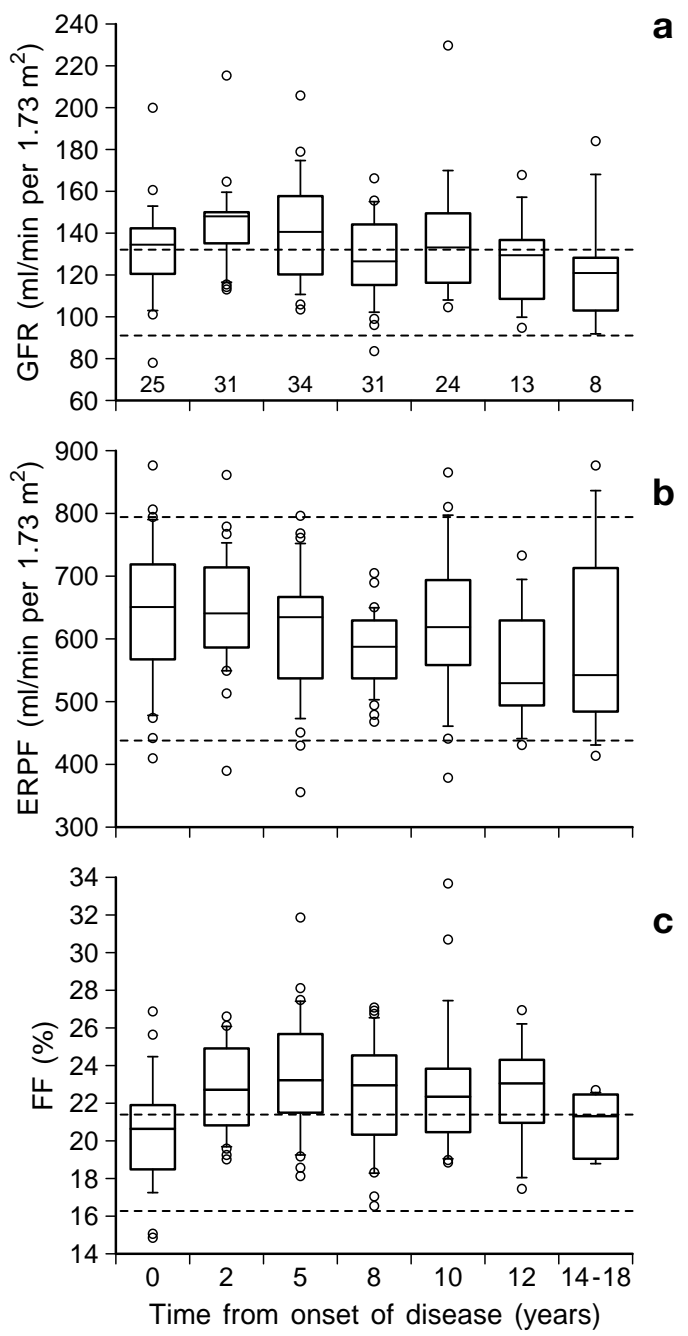

Fig. 2.a-c. Glomerular filtration rate (GFR), effective renal plasma flow (ERPF) and filtration fraction (FF) in all patients performed before and at time of the renal biopsy. The median values, 25 th, 75 th, and 10th and 90th centiles are shown. The dotted lines indicate the 10th and 90th centiles of 59 healthy control subjects. The number of patients included in each box is given just above th $\mathrm{x}$-axes of the GFR graph 


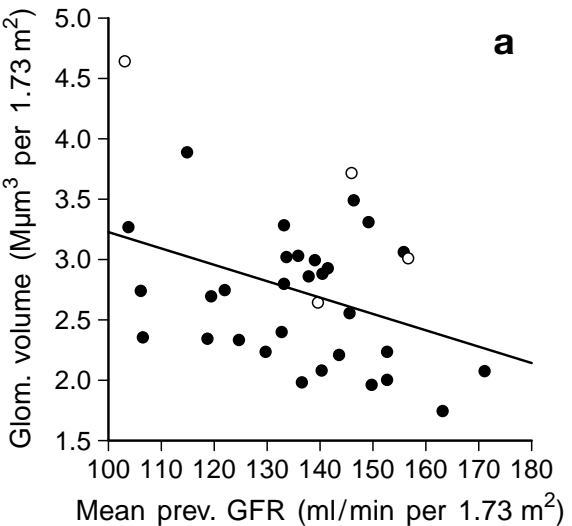

Fig.3a,b. Glomerular volume in relation to a. mean previous glomerular filtration rate (GFR) $(r=0.384, n=33, p<0.05)$ and b. mean previous effective renal plasma flow (ERPF) $(r=0.511, n=33, p<0.05)$. (O) four patients with IgA deposits. The correlation coefficient $(r)$ given is with the IgA deposit patients included

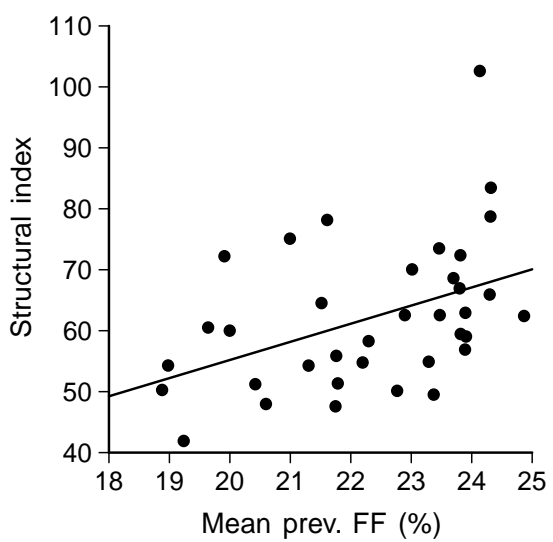

Fig.4. Structural index, calculated as $(\mathrm{BMT} / 10+100 \times$ $\mathrm{Vv}($ matrix/glom $)$ ), in relation to mean previous filtration fractions (FF) $(r=0.433, n=36, p<0.01)$

Morphometric parameters in relation to renal function. GV was inversely related to mean previous GFR and ERPF (Fig. 3). Since patients with IgA deposits had larger glomeruli, these patients are specially depicted in the figures. When mean previous GFR was related to GV (Fig. 3a), the $p$-value for the regression line changed from 0.0272 with the $\operatorname{IgA}$ patients included to 0.068 with the $\operatorname{Ig} \mathrm{A}$ patients excluded. The correlation between mean previous ERPF and GV was significant whether IgA patients were included or excluded (Fig. 3b).

There was a direct correlation between mean previous $\mathrm{FF}$ and $\mathrm{BMT}(r=0.407, p<0.02), \mathrm{Vv}(\mathrm{mes} /$ glom $)(r=0.431, p<0.01)$ and structural index (Fig.4). No significant correlations were found between mean previous GFR or ERPF and BMT or $\mathrm{Vv}$ (mes/glom).

When grouping the patients into those with microalbuminuria $(>15 \mu \mathrm{g} / \mathrm{min})$ and those without at time

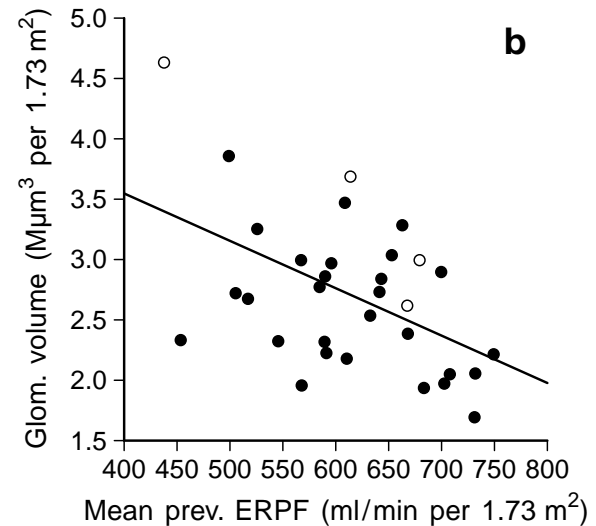

of renal biopsy, patients with microalbuminuria had thicker basal membranes $(580 \pm 52$ vs $486 \pm 20 \mathrm{~nm}$, $p<0.05)$, increased $\mathrm{Vv}$ (matrix/glom) $(12.1 \pm 0.9 \mathrm{vs}$ $10.4 \pm 0.4 \%, p<0.05)$, decreased Lv(slit pore/glom) $\left(0.286 \pm 0.013\right.$ vs $\left.0.367 \pm 0.011 \mu \mathrm{m}^{-2}, p<0.001\right)$, decreased $\mathrm{Sv}$ (pcap/glom) $\quad(0.126 \pm 0.007 \quad$ vs $\quad 0.147 \pm$ $\left.0.003 \mu \mathrm{m}^{-1}, p<0.01\right)$, and higher structural index $(70.1 \pm 6.0$ vs $59.0 \pm 2.1, p<0.05)$ than those without microalbuminuria. The total filtration surface area per glomerulus (the product of $\mathrm{Sv}$ (pcap/glom) and $\mathrm{GV}$ ) was not significantly different between microand nonalbuminuric patients $(0.353 \pm 0.033 \mathrm{vs}$ $0.379 \pm 0.022 \mathrm{Mum}^{2}$ ) due to somewhat larger glomerular volumes in the microalbuminuric group $(2.96 \pm$

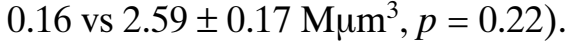

A direct correlation was found between foot process width and log UAE (Fig. 5 a) and an inverse correlation between $\mathrm{Lv}$ (slit pore/glom) and log UAE (Fig. 5b). If total slit pore length is calculated $(\mathrm{GV} \times$ $\mathrm{Lv}$ (slit pore/glom)) and related to $\log \mathrm{UAE}$ there is still a correlation, however, not significant $(r=0.333$, $p=0.0895)$.

Metabolic control in relation to morphometry and renal function. Figure 6 a shows the correlation between structural index and mean of all previously taken $\mathrm{HbA}_{1 \mathrm{c}}$. Significant correlations were also found between the mean of all $\mathrm{HbA}_{1 \mathrm{c}}$ and BMT and $\mathrm{Vv}(\mathrm{ma}-$ trix/glom $)(r=0.624, p<0.001$ and $0.44, p<0.01$, respectively).

There was also a significant correlation between mean previous $\mathrm{FF}$ and mean of all $\mathrm{HbA}_{1 \mathrm{c}}$ (Fig. 6b). $\mathrm{FF}$ at time of biopsy was also directly related to actual $\mathrm{HbA}_{1 \mathrm{c}}$ (Fig. 7) taken at the renal function test.

Patients with microalbuminuria at the time of renal biopsy had worse previous metabolic control than patients without microalbuminuria (mean $\mathrm{HbA}_{1 \mathrm{c}} 9.3 \pm 0.5$ vs $\left.7.9 \pm 0.2 \%, p<0.01\right)$.

Multiple linear regression analysis by two different regression models has been used to further analyse the influence of different variables on BMT and $\mathrm{Vv}$ (matrix/glom) as the outcome variables. Duration of diabetes, age at biopsy, mean previous FF and mean of all $\mathrm{HbA}_{1 \mathrm{c}}$ were used as independent vari- 


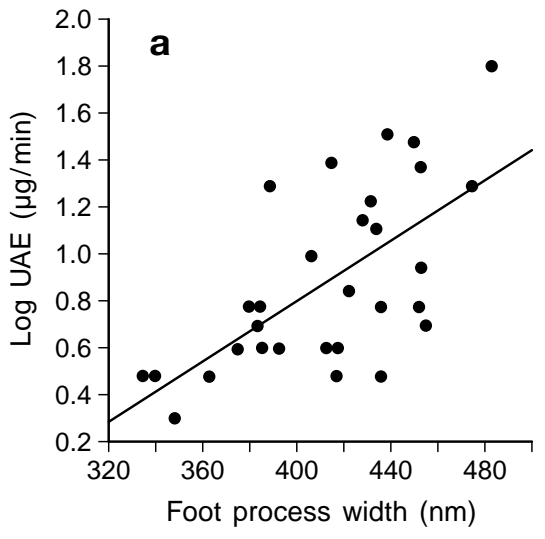

Fig.5a,b. Urinary albumin excretion (UAE), expressed in log values, in relation to $\mathbf{a}$. foot process width $(r=0.645, n=30$, $p<0.001)$ and b. length density of filtration slits Lv(slit pore/ glom $)(r=0.683, n=30, p<0.001)$

ables in both models. Table 1 shows the independent variables of importance for BMT as the outcome variable. $44 \%\left(r^{2}=0.44\right)$ of the variation in BMT is explained by metabolic control (mean of all $\mathrm{HbA}_{1 \mathrm{c}}$ ) and age at biopsy while mean previous $\mathrm{FF}$ and duration of disease were not found to be important explanatory factors. According to this model BMT increases with $61 \mathrm{~nm}$ with each per cent added of mean $\mathrm{HbA}_{1 \mathrm{c}}$ and $9 \mathrm{~nm}$ with each patient year. In the second model (Table 2) we found that $\mathrm{Vv}$ (matrix/ glom) correlated significantly to FF (mean previous FF) and duration of the disease and these two variables explained $28 \%$ of the variation in $\mathrm{Vv}$ (matrix/ glom). No significant effects were found from age at biopsy, mean $\mathrm{HbA}_{1 \mathrm{c}}$ and the interaction effect of mean previous $\mathrm{FF}^{*}$ mean $\mathrm{HbA}_{1 \mathrm{c}}$. $\mathrm{Vv}$ (matrix/glom)

Fig.6a,b. Metabolic control evaluated as a mean of all previous $\mathrm{HbA}_{1 \mathrm{c}}$ in relation to a. structural index, calculated as $(\mathrm{BMT} / 10+100 \times \mathrm{Vv}($ matrix/glom $)) \quad(r=0.626, \quad n=36, \quad p<$ $0.001)$ and b. mean previous filtration fractions (FF) $(r=$ $0.485, n=36, p<0.01)$

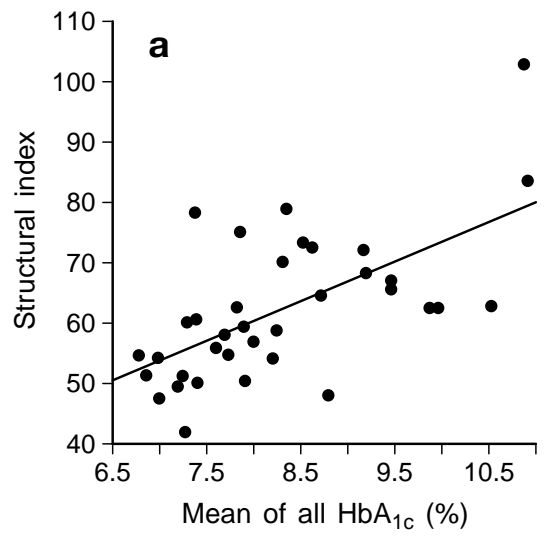

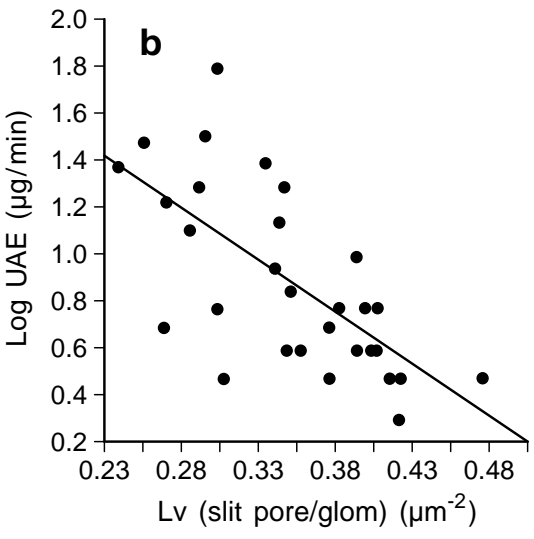

increased $0.6 \%$ with each per cent added of mean previous $\mathrm{FF}$ and $0.2 \%$ with each year of duration.

\section{Discussion}

This is the first report on renal biopsies in diabetic children before the stage of microalbuminuria and after long-term follow-up of their renal function determined at regular intervals by accurate methods.

Despite the fact that none of the patients in the present study had persistent microalbuminuria, basal membrane thickening as well as an increase of mesangial matrix were seen. We have not collected any of our own control material but we have compared our data with normal values from the literature. In renal biopsies from cadaveric as well as from living donors, mean values of BMT have been reported to be $305 \mathrm{~nm}$ [17], $343 \mathrm{~nm}$ [16], and $359 \mathrm{~nm}$ [18]. Corresponding mean values for $\mathrm{Vv}$ (matrix/glom) were reported to be $7 \%$ [18], 7.1\% [19], 8.6\% [16] and 9\% [17]. These donors were, however, mostly older than our patients. Steffes et al. [19] showed a slight increase in BMT with age up to the fourth decade of life. Thus, normal control values for BMT in the age group of our patients could be expected to be lower than those presented here, which would imply that most of our patients had increased BMT. In contrast to Rudberg et al. [20] we found no correlation between BMT and duration of disease.

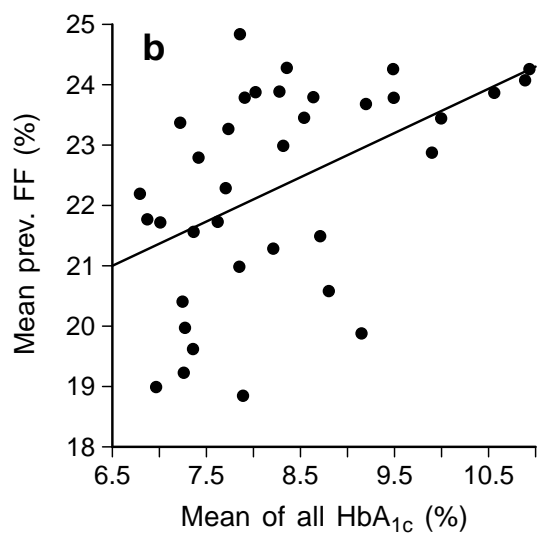




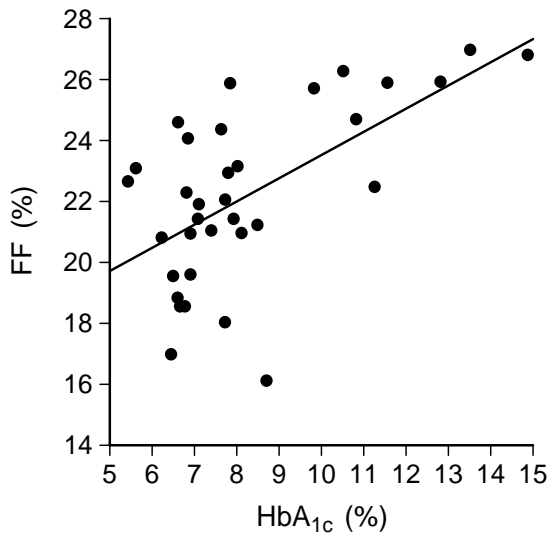

Fig. 7. Metabolic control evaluated as $\mathrm{HbA}_{1 \mathrm{c}}$ in relation to the filtration fraction, FF, at time of biopsy $(r=0.601, n=34, p<$ $0.001)$

Table 1. The estimated regression coefficients and corresponding $95 \%$ confidence interval of mean $\mathrm{HbA}_{1 \mathrm{c}}$ and age at biopsy as independent variables of importance for BMT

\begin{tabular}{lccr}
\hline $\begin{array}{l}\text { Independent } \\
\text { variable }\end{array}$ & Estimate & $\begin{array}{l}\text { 95\% confidence } \\
\text { interval }\end{array}$ & $p$-value \\
\hline Mean $\mathrm{HbA}_{1 \mathrm{c}}$ & 61 & $36-85$ & $<0.001$ \\
Age & 9 & $0-20$ & 0.097 \\
\hline
\end{tabular}

Table 2. The estimated regression coefficients and corresponding $95 \%$ confidence interval of mean previous filtration fraction $(\mathrm{FF})$ and duration of disease as independent variables of importance for $\mathrm{Vv}$ (matrix/glom)

\begin{tabular}{llll}
\hline $\begin{array}{l}\text { Independent } \\
\text { variable }\end{array}$ & Estimate & $\begin{array}{l}\text { 95\% confidence } \\
\text { interval }\end{array}$ & $p$-value \\
\hline Mean previous FF & 0.60 & $0.25-0.95$ & 0.0018 \\
Duration of disease & 0.22 & $0.01-0.42$ & 0.0437 \\
\hline
\end{tabular}

We found a significant difference in BMT and $\mathrm{Vv}$ (matrix/glom) when comparing patients with and without microalbuminuria at the time of biopsy, but also patients without microalbuminuria seemed to show thicker basal membranes and increased $\mathrm{Vv}$ (matrix/glom) compared with reported normal values [16-18]. These results are consistent with those of Walker et al. [21] and Fioretto et al. [22] but Østerby reports in her review of pooled data from a number of studies from her laboratory [23], increased BMT in some of the normoalbuminuric diabetic patients but a mesangial matrix volume entirely within the normal range. Chavers et al. [24] found total overlapping in BMT and mesangial volume in diabetic patients with and without microalbuminuria. This is in variance with studies of Walker et al. [21] and Østerby [23] who report clear differences between normoalbuminuric and microalbuminuric patients. The differences in results between different studies may be caused by differences in duration of diabetes and in the number and matching of control subjects.

The correlation between BMT and Vv(matrix/ glom), found in the present study and by Walker et al. [21], support the statement presented by $\emptyset$ sterby that changes in peripheral basal membrane and in mesangial matrix develop in concert and both contribute to the early stage of glomerulopathy in patients with microalbuminuria [23].

Renal diseases other than diabetic nephropathy have been reported in diabetic patients $[25,26]$ such as immune complex glomerulonephritis, membraneous nephropathy and others. The authors claim that the biochemically altered glomerular basement membrane is more permeable to macromolecules thus favouring deposition of antigen or complexes along glomerular basement membrane. Findings of IgA-deposits were reported by Gans et al. [27] in five elderly patients in a group of $47(10.6 \%)$ nonblack diabetic patients. Among 1286 non-diabetic kidney biopsies performed during the same time period, they found an incidence of $8.6 \%$ with $\operatorname{IgA}$ nephropathy [27]. The authors claim that the occurrence of IgA nephropathy in diabetes cannot be a coincidence. In a European study of 250 consecutive autopsy cases without known renal disease, the frequency of $\operatorname{IgA}$ deposits was found to be $4.8 \%$ [28]. We found in the present material 4 out of 36 diabetic patients, i.e. $11 \%$, with IgA deposits. Among 202 diabetic patients having undergone a renal biopsy at Huddinge Hospital between July 1982 and July 1993, 24 were diagnosed with IgA nephropathy $(12 \%), 16$ of whom had insulin-dependent and 8 non-insulin-dependent diabetes mellitus (unpublished data).

In most studies where renal function is related to structural changes, no correlations have been reported probably because the renal functional investigation was performed only once and mostly in connection with the biopsy $[17,23,29]$. Furthermore the patients mostly had a longer duration of the disease and represent a later stage of nephropathy [30]. We have related our data to mean previous GFR or FF, which thus reflects the renal function during the whole period before the biopsy. Furthermore we have performed the biopsy at a very early stage of the disease in an unselected group of patients among whom a fraction of approximately $30 \%$ will progress to overt nephropathy. We found correlations between BMT, Vv(matrix/glom) and structural index to mean previous FF which indicates that longstanding hyperfiltration (increased GFR) without simultaneous hyperperfusion (increased ERPF), i.e. increased FF, is a contributing factor for the development of glomerular changes. Thus, it seems that previous FF is of greater importance than previous GFR indicating the importance of determining both GFR and ERPF in diabetic patients. 
Increased GFR and FF have been reported in IDDM from start of the disease [8, 31-36]. ERPF has been reported to be increased [33, 35-37], normal $[8,38]$ and decreased [39]. The causes of the hyperfiltration have been widely discussed [40]. In the present study performed at around 10 years' duration, high GFR and FF were still found. At time of renal biopsy some of our diabetic patients showed microalbuminuria and those also showed previous hyperfiltration and high FF. Rudberg et al. [41] has previously reported that the only predictor to develop albuminuria was hyperfiltration after 8 years' duration. Chiarelli et al. [42] followed two groups of diabetic children and adolescents with the same duration of disease over a 10 -year period. The patients were divided into 23 with hyperfiltration (GFR $>140 \mathrm{ml} / \mathrm{min}$ per $1.73 \mathrm{~m}^{2}$ ) and 23 age- and sex-matched diabetic patients without hyperfiltration. Of the 23 hyperfiltering patients 7 developed microalbuminuria while only 1 in the non-hyperfiltering group. They concluded that persistent glomerular hyperfiltration is a risk factor for the development of microalbuminuria [42]. Mogensen [43] reported that patients who had had marked hyperfiltration about 13 years earlier had microalbuminuria and decreased GFR at follow-up. He proposed that marked hyperfiltration may contribute to late glomerular damage [43]. Rudberg et al. [44] recently reported that in adolescents with hyperfiltration in the normoalbuminuric stage, a decline in GFR may be an expression of more advanced diabetic glomerulopathy. In that study, however, the decline is based on only two GFR measurements performed with different techniques and approximately 3 years apart. In the present study we did not find any correlation between yearly change in GFR or ERPF and any morphometric parameters.

It could be expected that hyperfiltration is connected with large glomeruli. Instead we found a weak, inverse correlation between mean previous GFR and GV. Some of the patients with hyperfiltration had small glomerular volumes. Bilous et al. [45] reported no significant differences in $\mathrm{GV}$ between control subjects and diabetic patients with or without nephropathy and with a relatively short disease duration (14-16 years), while nephropathic subjects with longer duration (24-26 years), however, showed significantly enlarged GV. In the first group of nephropathic subjects, GV did not correlate with the number of sclerotic glomeruli which was the case in the subjects with longer duration. The patients who developed nephropathy at an early age might thus be those with an incapacity to increase their glomerular volume which could be fatal for the glomeruli. Based on the above mentioned studies relating hyperfiltration to a greater risk for nephropathy, as well as our findings that high mean previous FF correlates to an increase in structural index (i.e. relative increase of mesangial matrix per glomerulus), patients in our study who both hyperfiltrate and show small glomeruli may represent the subset of patients who will later develop nephropathy. This is in agreement with studies in more advanced nephropathy where mesangial expansion in glomeruli without the capacity to increase in size will result in more advanced nephropathic changes [46]. In autopsies from diabetic patients with overt nephropathy, the largest glomeruli were the least affected by diabetic glomerulopathy [47]. Thus, if mesangial volume fraction increase is totally compensated for by glomerular enlargement, this does not result in loss of filtration surface [23].

The mechanisms and the structural counterpart of the increased permeability to albumin have not been identified. We found a direct correlation between foot process width and log UAE and an inverse correlation between $\log \mathrm{UAE}$ and filtration slit $\mathrm{Lv}$ (slit pore/glom). Ellis et al. [48] found increased foot process width in patients with overt albuminuria and they found slightly wider foot processes in microalbuminuric diabetic patients compared to control subjects while filtration slit length density was similar in control subjects and microalbuminuric diabetic patients but decreased in patients with overt proteinuria. Bjørn et al. [49] found an overall tendency of wider foot process width in patients with increased albumin excretion rate and a correlation between foot process width on mesangium and log UAE but they did not think that could explain the mechanism of albumin leakage.

It has been suggested that maladaptive changes of the podocytes are closely linked to the development of glomerular sclerosis [50, 51]. A fundamental reason that the podocytes exhibit degenerative changes when challenged to glomerular hypertrophy and hypertension [52] is that the podocytes possess no or little capacity to replicate and can therefore adapt only by hypertrophy. This adaptive hypertrophy of the podocytes is always associated with an effacement of their foot processes and a decrease in permselectivity. For instance, Tenschert et al. [53] found after subtotal nephrectomy in rats a strong inverse correlation between filtration slit length (i.e. increase in foot process width) and albuminuria. Thus, the demonstration of an increase in foot process width indirectly suggests that related glomeruli are hypertrophied and/or exposed to increased intracapillary pressures. Both these processes have been accepted to take place in the diabetic glomerulus. Furthermore it has been shown that the glomerular capillary barrier is highly sensitive to elevations of hydrostatic pressure; minute elevations of the intracapillary pressure results in a markedly increased permeability for albumin [54]. Taking these observations together and relating them to our data that an increase in mean previous FF related to an increase in UAE, we find it rational to suggest that microalbuminuria in diabetic 
patients is, among other causes, the result of an increase in intracapillary glomerular pressure.

The connection between poor metabolic control and morphological changes has been described previously [17]. Our findings of the worst metabolic control in the patients with microalbuminuria confirm the findings in other studies $[21,40,55]$. The relation of poor metabolic control and hyperfiltration that was found in the present study is in agreement with others $[16,40]$. When performing multiple regression analyses we found that metabolic control seemed to be an important factor for the increase in basal membrane thickness while increase in mean previous FF seemed to be most important for the increase in $\mathrm{Vv}$ (matrix/glom). This could be interpreted as indicating that changes in basal membrane thickness could vary with metabolic control and perhaps an improved metabolic control in early stages of the disease might decrease the thickening of the membranes. The more important influence of FF on $\mathrm{Vv}$ (matrix/glom) could be interpreted as indicating that the hyperfiltration and thereby the increase in filtration pressure within the glomerulus might directly influence mesangial matrix.

In conclusion the study has been performed in normoalbuminuric patients of whom only around $30 \%$ will develop diabetic nephropathy. Despite the investigation performed in this early phase of the disease, we found significant structural abnormalities such as thickening of the glomerular basal membranes as well as increased mesangial matrix volume fractions. It seemed as if long-term hyperfiltration, specially high FF, and poor metabolic control were predictive of structural changes. Furthermore if mesangial matrix volume increases in glomeruli of small or normal size, the risk of developing nephropathy seems to increase.

Acknowledgements. We are grateful to Ruth Østerby for valuable comments and advice. The study was supported by grants from the Trygg-Hansa Research Fund, the Karolinska Institute, the Samariten Foundation, the Mayflower Foundation, the Tornspiran Foundation, the Child Diabetes Fund and the Swedisch Medical Research Council (no. 6864).

\section{References}

1. Andersen AR, Sandahl Christiansen J, Andersen JK, Kreiner S, Deckert T (1983) Diabetic nephropathy in type I (insulin-dependent) diabetes: an epidemiological study. Diabetologia 25: 496-501

2. Krolewski AS, Warram JH, Christlieb AR, Busick EJ, Kahn CR (1985) The changing natural history of nephropathy in type I diabetes. Am J Med 78: 785-794

3. DCCT (1993) The effect on intensive treatment of diabetes on the development and progression of long-term complications in insulin-dependent diabetes mellitus. $\mathrm{N}$ Engl J Med 329: 977-986

4. Bojestig M, Arnqvist HJ, Hermansson G, Karlberg BE, Ludvigsson J (1994) Declining incidence of nephropathy in insulin-dependent diabetes mellitus. N Engl J Med 330: $15-18$

5. Reichard P, Nilsson B-Y, Rosenqvist U (1993) The effect of long-term intensified insulin treatment on the development of microvascular complications of diabetes mellitus. N Engl J Med 329: 304-309

6. Rossing P, Rossing K, Jacobsen P, Parving H-H (1995) Unchanged incidence of diabetic nephropathy in IDDM patients. Diabetes 44: 739-743

7. Berg U, Bohlin A-B (1982) Renal hemodynamics in minimal change nephrotic syndrome in childhood. Int J Ped Nephrol 3: 187-192

8. Berg UB, Thalme B (1984) Early renal functional changes in children with insulin-dependent diabetes mellitus - Their relation to metabolic control. Int J Ped Nephrol 5: 15-21

9. Hilger HH, Klümper JD, Ullrich KJ (1958) Wasserrückresorption und Ionentransport durch die Sammelrohrzellen der Säugetiernieren. Pflügers Arch 267: 218-237

10. Smith H, Fingelstein N, Aliminosa L, Crawford B, Graber M (1945) The renal clearances of substituted hippuric acid derivates and other aromatic acids in dog and man. J Clin Invest 24: 388-404

11. Jeppsson JO, Jerntorp P, Sundkvist G, Englund H, Nylund V (1986) Measurement of hemoglobin A1c by a new liquid-chromatographic assay: methodology, clinical utility, and relation to glucose tolerance evaluated. Clin Chem 32: 1867-1872

12. Gundersen HJH, Jensen EB (1987) The efficiency of sampling in stereology and its prediction. J Microsc 147: 229-263

13. Brismar H, Patwardhan A, Jaremko G, Nyengaard J (1996) Thickness estimation of fluorescent sections using a CSLM. J Microsc 184: 106-116

14. Østerby R, Gundersen H (1980) Fast accumulation of basement membrane material and the rate of morphological changes in acute experimental diabetic glomerular hypertrophy. Diabetologia 18: 493-500

15. Jensen EB, Gundersen HJG, Østerby R (1979) Determination of membrane thickness distribution from orthogonal intercepts. J Microsc 115: 19-33

16. Østerby R, Parving H-H, Hommel E, Jørgensen HE, Løkkegaard H (1990) Glomerular structure and function in diabetic nephropathy. Diabetes 39: 1057-1063

17. Bangstad H-J, Østerby R, Dahl-Jørgensen K et al. (1993) Early glomerulopathy is present in young, type 1 (insulindependent) diabetic patients with microalbuminuria. Diabetologia 36: 523-529

18. Steffes MW, Bilous RW, Sutherland DER, Mauer SM (1992) Cell and matrix components of the glomerular mesangium in type I diabetes. Diabetes: 41: 679-684

19. Steffes MW, Barbosa J, Basgen JM, Sutherland DER, Najarian JS, Mauer SM (1983) Quantitative glomerular morphology of the normal human kidney. Lab Invest 49: 82-86

20. Rudberg S, Østerby R, Dahlquist G, Nyberg G, Persson B (1997) Predictors of renal morphological changes in the early stage of microalbuminuria in adolescents with IDDM. Diabetes Care 20: 265-271

21. Walker JD, Close CF, Jones SL et al. (1992) Glomerular structure in type-1 (insulin-dependent) diabetic patients with normo- and microalbuminuria. Kidney Int 41: 741-748

22. Fioretto P, Steffes MW, Mauer M (1994) Glomerular structure in nonproteinuric IDDM patients with various levels of albuminuria. Diabetes 43: 1358-1364

23. Østerby R (1992) Glomerular structural changes in type 1 (insulin-dependent) diabetes mellitus: causes, consequences, and prevention. Diabetologia 35: 803-812

24. Chavers BM, Bilous RW, Ellis EN, Steffes MW, Mauer SM (1989) Glomerular lesions and urinary albumin excretion 
in type I diabetes without overt proteinuria. N Engl J Med 320: 966-970

25. Sabnis SG, Antonovych TT (1983) Diabetic nephropathy with superimposed immune complex glomerulonephritis. Southern Med J 76: 456-461

26. Kasinath A, Mujais SK, Spargo BH, Katz AI (1983) Nondiabetic renal disease in patients with diabetes mellitus. Am J Med 75: 613-617

27. Gans R, Ueda Y, Ito S et al. (1992) The occurrence of IgAnephropathy in patients with diabetes mellitus may not be coincidental: A report of five cases. Am J Kidn Dis 20: 255-260

28. Waldherr R, Ilkenhans C, Ritz E (1992) How frequent is glomerulonephritis in diabetes mellitus type II? 37: 271-273

29. Mauer SM, Mogensen CE, Viberti G-C (1992) Introduction: Symposium on the progress in diabetic nephropathy. Kidney Int 41: 717-718

30. Mauer SM, Sutherland DER, Steffes MW (1992) Relationship of systemic blood pressure to nephropathology in insulin-dependent diabetes mellitus. Kidney Int 41: 736-740

31. Stalder G, Schmid R (1959) Severe functional disorders of glomerular capillaries and renal hemodynamics in treated diabetes mellitus during childhood. Ann Paediat 193: 129-138

32. Mogensen CE (1976) Renal function changes in diabetes. Diabetes 25 [Suppl 2]: 872-879

33. Sandahl Christiansen J, Frandsen M, Parving H-H (1981) The effect of intravenous insulin infusion on kidney function in insulin-dependent diabetes mellitus. Diabetologia 20: 199-204

34. Dahlquist G, Aperia A, Persson B (1984) Renal function and albuminuria in diabetic children and adolescents: relation to metabolic control and duration. Diabetic Nephropathy 3: 117-122

35. Johansson B-L, Berg U, Freyschuss U, Hall K, Troell S (1990) Factors related to renal haemodynamics in young type-1 diabetes mellitus patients. Ped Nephrol 4: 589-592

36. Laborde K, Levy-Marchal C, Kindermans C, Dechaux M, Czernichow P, Sachs C (1990) Glomerular function and microalbuminuria in children with insulin-dependent diabetes. Ped Nephrol 4: 39-43

37. Mogensen CE (1971) Glomerular filtration rate and renal plasma flow in short-term and long-term juvenile diabetes mellitus. Scand J Clin Lab Invest 28: 91-100

38. Mogensen CE, Andersen MJF (1973) Increased kidney size and glomerular filtration rate in early juvenile diabetes. Diabetes 22: 706-712

39. Ditzel J, Junker K (1972) Abnormal glomerular filtration rate, renal plasma flow, and renal protein excretion in recent and short-term diabetics. Brit Med J 2: 13-19
40. Mogensen CE (1989) Hyperfiltration, hypertension, and diabetic nephropathy in IDDM patients. Diab Nutr Metab 2: $227-244$

41. Rudberg S, Persson B, Dahlquist G (1992) Increased glomerular filtration rate as a predict or of diabetic nephropathy An 8-year prospective study. Kidney Int 41: 822-828

42. Chiarelli F, Verrotti A, Morgese G (1995) Glomerular hyperfiltration increases the risk of developing microalbuminuria in diabetic children. Pediatr Nephrol 9: 154-158

43. Mogensen CE (1986) Early glomerular hyperfiltration in insulin-dependent diabetics and late nephropathy. Scand J Clin Lab Invest 46: 201-206

44. Rudberg S, Østerby R (1997) Decreasing glomerular filtration rate-an indicator of more advanced diabetic glomerulopathy in the early course of microalbuminuria in IDDM adolescents? Nephrol Dial Transplant 12: 1149-1154

45. Bilous RW, Mauer SM, Sutherland DER, Steffes MW (1989) Mean glomerular volume and rate of development of diabetic nephropathy. Diabetes 38: 1142-1147

46. Steffes MW, Østerby R, Chavers B, Mauer M (1989) Mesangial expansion as a central mechanism for loss of kidney function in diabetic patients. Diabetes 38: 1077-1081

47. Gundersen HJG, Østerby R (1977) Glomerular size and structure in diabetes mellitus. II. Late abnormalities. Diabetologia 13: 43-48

48. Ellis EN, Steffes MW, Chavers B, Mauer SM (1987) Observations of glomerular epithelial cell structure in patients with type I diabetes mellitus. Kidney Int 32: 736-741

49. Bjørn SF, Bangstad HJ, Hanssen KF et al. (1995) Glomerular epithelial foot processes and filtration slits in IDDM patients. Diabetologia 38: 1197-1204

50. Fries J, Sandstrom D, Meyer T, Rennke H (1989) Glomerular hypertrophy and epithelial cells injury modulate progressive glomerulosclerosis. Lab Invest 60: 205-218

51. Nagata M, Schärer K, Kriz W (1992) Glomerular damage after uninephrectomy in young rats. I. Hypertrophy and distortion of capillary architecture. Kidney Int 42: 136-147

52. Kriz W, Elger M, Mundel P, Lemley KV (1995) Structurestabilizing forces in the glomerular tuft. J Am Soc Nephrol 5: 1731-1739

53. Tenschert S, Elger M, Lemley KV (1995) Glomerular hypertrophy after subtotal nephrectomy: relationship to early glomerular injury. Virchows Arch 426: 509-517

54. Johnsson E, Rippe B, Haraldsson B (1994) Reduced permselectivity in isolated perfused rat kidneys following small elevation of glomerular capillary pressure. Acta Physiol Scand 150: 201-209

55. Wiseman M, Viberti G, Mackintosh D, Jarett RJ, Keen H (1984) Glycaemia, arterial pressure and micro-albuminuria in type 1 (insulin-dependent) diabetes mellitus. Diabetologia 26: 401-405 